\title{
NEW APPROACH FOR COMPUTER-AIDED STATIC BALANCING OF TURBINES ROTORS
}

\author{
Salah AMROUNE ${ }^{1,2}$, Ahmed BELAADI ${ }^{3,4}$, Noureddine MENASRI ${ }^{1,2}$, Moussa ZAOUI ${ }^{1,2}$, \\ Barhm MOHAMAD ${ }^{5}$, Houari AMIN ${ }^{1}$ \\ ${ }^{1}$ University of M'sila; B.P 166 ICHBELIA. M'sila 28000 Algeria e-mail: salah.amroune@ univ-msila.dz, \\ noureddine.menasri@univ-msila.dz, moussa.zaoui@univ-msila.dz, amingenie14@gmail.com \\ ${ }^{2}$ Laboratoire de Matériaux et Mécanique des Structures (LMMS), Université de M'sila. Algérie \\ ${ }^{3}$ Université 20 août 1955-Skikda, B.P.26 route El-HadaiekSkikda-Algérie. e-mail: ahmedbelaadi1@ yahoo.fr \\ ${ }^{4}$ Silicates, Polymers and Nanocomposites Laboratory (SPNL), University of 08 Mai 1945, Guelma-Algérie, \\ ${ }^{5}$ Faculty of Mechanical Engineering and Informatic-University of Miskolc, 3515 Miskolc-Hungary. e-mail: \\ pywand@gmail.com
}

Abstract

The balancing operation consists in improving the distribution of the rotor masses so that the free centrifugal forces around the rotor axis, imposed by the manufacturer, do not exceed the tolerances allowed by the standards. In this paper we propose algorithms for the distribution of the turbine blades from data from an electronic scale which allows to measure the static moment of the blades, these algorithms aim to find the correction weight and the angle of position of the correction mass, we also propose a simulation of the distribution of the blades of a turbine to get an idea on the assembly. This operation is necessary in the case of a repair of the rotors or in the assembly of the new flexible rotors. Using a MATLAB calculation code.

Keywords: mass unbalance, compensation, balancing mass rotor, correction masses.

\section{INTRODUCTION}

Turbines play very important roles in the industry and are used primarily to produce electric power, which is achieved by gas turbines or steam turbines. The use of a turbine, like any rotating power machine, must include a scheduled program of periodic inspections, repair and replacement of defective parts to ensure maximum machine reliability.

The many problems of intervention are found at the level of the rotating machines which have a relation with the balancing process which is considered at this moment very necessary for the practice of all the rotors, whether to extend the life of the machine, which imposes the optimization of the exploitation and the quality of productions. Balancing is a process of controlling the mass distribution of a rotor and improving it to maintain the forces and vibrations caused by unbalance within acceptable limits [1-5].

Rotor balancing is a fundamental requirement for the smooth operation of turbo machinery. Ideally, in the operation of all rotating machinery, the inertia axis of the rotor lies along the rotor spin axis. In actuality, this does not occur, and centrifugal forces and moments are generated which can result in high forces transmitted to the bearings and the supporting structure. Excessive rotor unbalance may lead to large amplitudes of motion or even failure of the shaft, bearings, and the foundation. Unbalance and shaft misalignment are recognized as two of the major factors that can lead to machinery malfunction and even catastrophic failure. [6].

The distribution of blades on the rotor of a turbine is a fundamental element for the balancing behavior of this rotor, how can we develop predictive maintenance with a new solution. Because of the strong requirements of reliability, safety, and maintenance of this equipment, manufacturers must have tools to ensure the proper functioning of these machines. [7-10].

Several authors have begun work on balancing rotors, Van de Vegte has presented a concept of automatic rotor balancing [11-13], there is also more or less rational designs of the control mechanisms, allowing at least theoretical implementation of the process [14-18] were developed. The tests on automatic balancing were performed by Sperling et al [19, 20], Chung et al [21], Cade [22], Lee and Van Moorhem [23].

In this work, we focus on static balancing turbine rotors; our contribution is to develop a calculation code on MATLAB which is based on six distribution algorithms to make a graphical simulation of the repair of the blade to calculate the mass to add and the position of the correction angle to minimize unbalance. These two parameters (the mass to be added and the position of the correction angle) make it easier to mount blades in a new rotor 
before operation or during a scheduled service overhaul.

\section{EXPERIMENTAL TECHNIQUES}

\subsection{Measurement of static moments}

Before starting the assembly of the blades of a rotor wheel of a turbine (Figure 1), we proceed to the numbering of the blades one by one knowing that we have in this study, three series of 40, 70 and 120 blades, then we go to the measurement of the static moments of the three series of blades with the help of an electronic scale type WM (Figure 2), the latter gives us values with an accuracy of the order of $0.001 \mathrm{~g} . \mathrm{mm}$. The data acquired by the balance is stored in a database, either directly on a microcomputer, if the scale is connected to a PC or the values are noted on a sheet of paper in the form of a table for later use in a Matlab calculation code using a well-chosen algorithm that gives us the best result in terms of correction mass and correction angle.

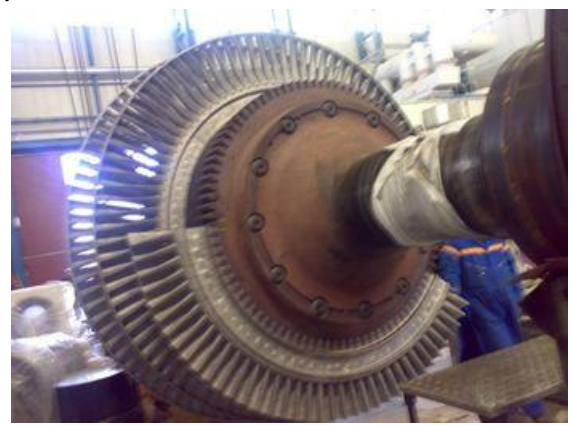

Fig. 1. Wheel of a turbine rotor MEI Sonelgaz M'sila.

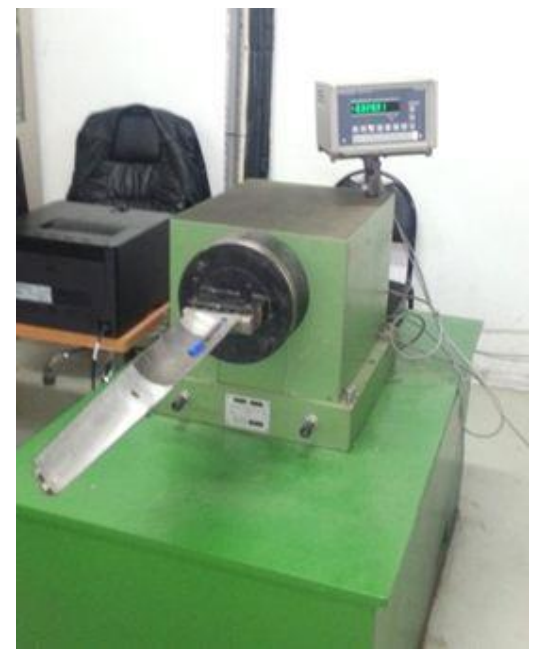

Fig. 2. Measurement of static moments with a WM scale.

One possibility of correction is to move the axis of rotation of the rotor towards the axis of inertia. This procedure - called mass centering - is sometimes used when balancing in one or two planes. The rotor is first positioned in any way, the unbalance is determined with respect to the axis of rotation thus defined, then the rotor is moved during the rotation so that the two axes coincide, and the center point is then executed. When other elements of the rotor are then machined (centering, bearing seats, etc.), the new unbalance thus created must be compensated. The most common approach, however, is to bring the axis of inertia of the axis of rotation of the rotor by removal, displacement or addition of material. The unbalance of the rotor system is the product of the rotor mass, $\mathrm{M}$, and the distance, $r$. When this product exceeds commended amount, the rotor is said to be unbalanced, to calculate this mass and the positioning angle of the mass of correction one uses two methods:

\subsection{Analytical method}

The analytical method consists of calculating the static moments $\mathrm{M}_{\mathrm{i}}$ and decomposing on the $\mathrm{x}$ and y axes (Figure 3 ).
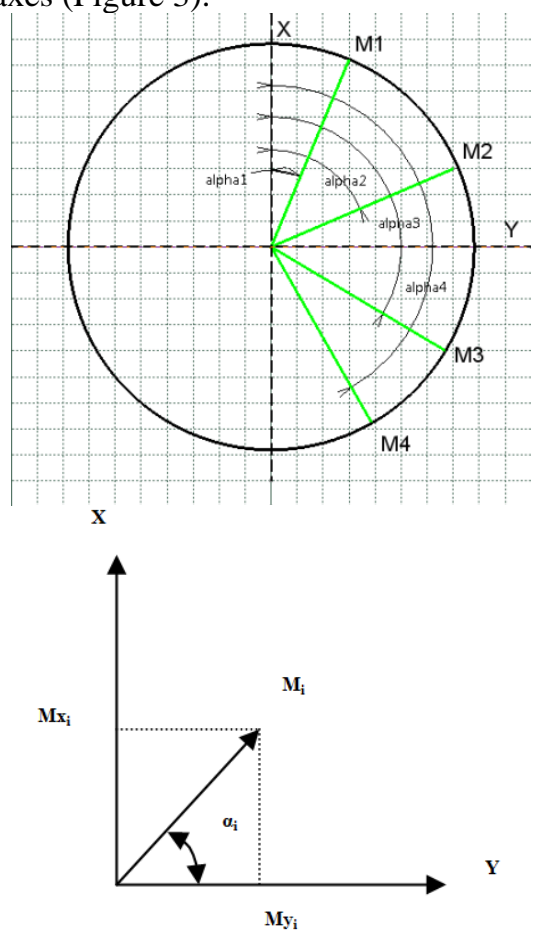

Fig. 3. Decomposition of static moments.

The values of the static moments and their projections on the $\mathrm{x}$ and $\mathrm{y}$ axes are grouped together in Table 1.

Table 1. Calculation of static moments

\begin{tabular}{|c|c|c|c|c|}
\hline $\begin{array}{c}\text { Pos } \\
\mathrm{N}^{\circ}\end{array}$ & $\begin{array}{c}\text { Mome } \\
\mathrm{nt} \mathrm{M}_{\mathrm{i}}\end{array}$ & $\begin{array}{c}\text { Angle } \\
\alpha\end{array}$ & $\mathrm{Mx}_{\mathrm{i}}=\mathrm{M}_{\mathrm{i}} \mathrm{x} \sin \alpha_{\mathrm{i}}$ & $\mathrm{My}_{\mathrm{i}}=\mathrm{M}_{\mathrm{i}} \mathrm{x} \cos \alpha_{\mathrm{i}}$ \\
\hline 1 & $\mathrm{M}_{1}$ & 0 & $\mathrm{Mx}_{1}$ & $\mathrm{My}_{1}$ \\
\hline 2 & $\mathrm{M}_{2}$ & $2 \alpha$ & $\mathrm{Mx}_{2}$ & $\mathrm{My}_{2}$ \\
\hline 3 & $\mathrm{M}_{3}$ & $3 \alpha$ & $\mathrm{Mx}_{3}$ & $\mathrm{My}_{3}$ \\
\hline 4 & $\mathrm{M}_{4}$ & $4 \alpha$ & $\mathrm{Mx}_{4}$ & $\mathrm{My}_{4}$ \\
\hline 5 & $\mathrm{M}_{5}$ & $5 \alpha$ & $\mathrm{Mx}_{5}$ & $\mathrm{My}_{5}$ \\
\hline & & & & \\
\hline & & & & $\mathrm{My}_{\mathrm{n}}$ \\
\hline $\mathrm{n}$ & $\mathrm{M}_{\mathrm{n}}$ & $\mathrm{n} \alpha$ & $\mathrm{Mx}_{\mathrm{n}}$ & $\sum_{i=0}^{n} M y i$ \\
\hline & & & $\sum_{i=}^{n} M x i$ & \\
\hline
\end{tabular}

So:

Module $={\sqrt{\left(\sum_{i=0}^{n} M x i\right)^{2}+\left(\sum_{i=0}^{n} M y i\right)}}^{2}$ 
Phase $(\alpha)=\operatorname{Arctg}\left(\frac{\left(\sum_{i=0}^{n} M x i\right)}{\left(\sum_{i=0}^{n} M y i\right)}\right)$

We assume that:

$\mathrm{n}$ : the number of blades.

M: the value of the static moment.

$\alpha$ : Angle (the position of the correction mass relative to the rotating mark reference)

\subsection{Graphical method}

The graphical method consists in choosing a well-defined scale then, we draw parallels to the moment vectors of each blade, and the established condition must be the parallelogram must close (Figure 4).

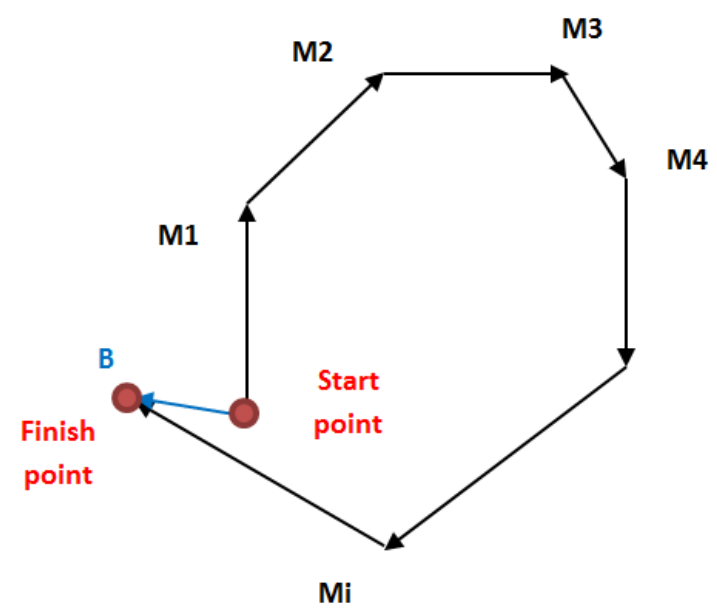

Fig. 4. Graphical representation of the moments.

For our case we use the analytical method because it is very simple to integrate mathematical formulas on a computer program, on the other hand if we use the graphical method for cases where there is a large number of blades in a wheel of the turbine, the representation will be complicated.

\section{RESULTS AND DISCUSSIONS}

To balance such a turbine rotor, it is necessary to reduce its centre of gravity on the axis of rotation by placing a balancing mass opposite the centre of gravity with respect to the axis of rotation, to find this mass will require to make several tests with masses of different value, To achieve this objective, the data that is acquired by the electronic balance according to a preselected algorithm is entered, the blade distribution algorithms are shown in (fig. 5afig 5f). These algorithms are integrated in the MATLAB computation code which helps us to solve the rotor unbalance problem. Fig 5a show that the assembly of the blades follows a distribution that divides the wheel into two decreasing sectors, that is to say, divide the number of blades $(\mathrm{N})$ by two, the maximum value of the moment $\mathrm{m} 1$ (max) occupies the first position $\mathrm{N}\left(90^{\circ}\right)$, then the second value $\mathrm{m} 2(\max )$ occupies the position $\mathrm{N} / 2+1$ $\left(270^{\circ}\right)$.

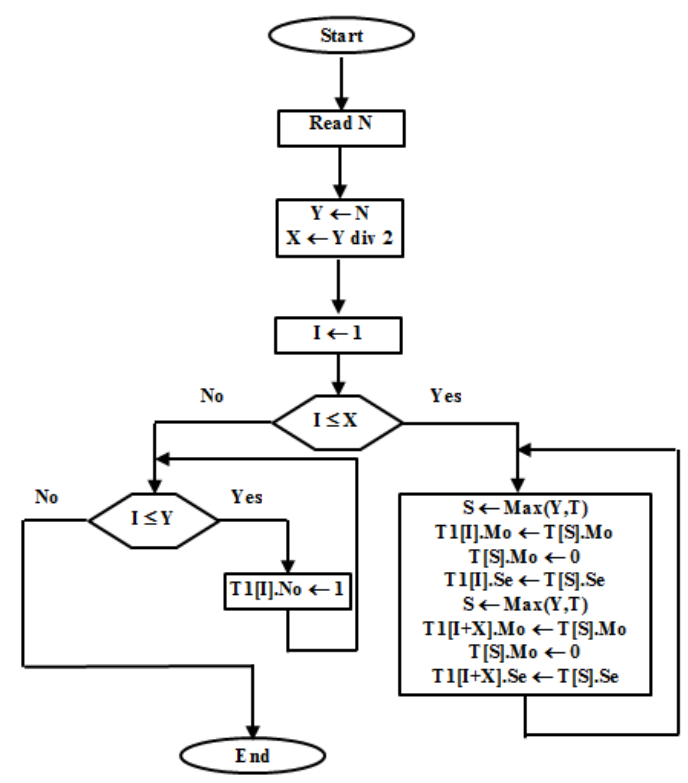

Fig. 5a. Algorithm 1 blades distribution.

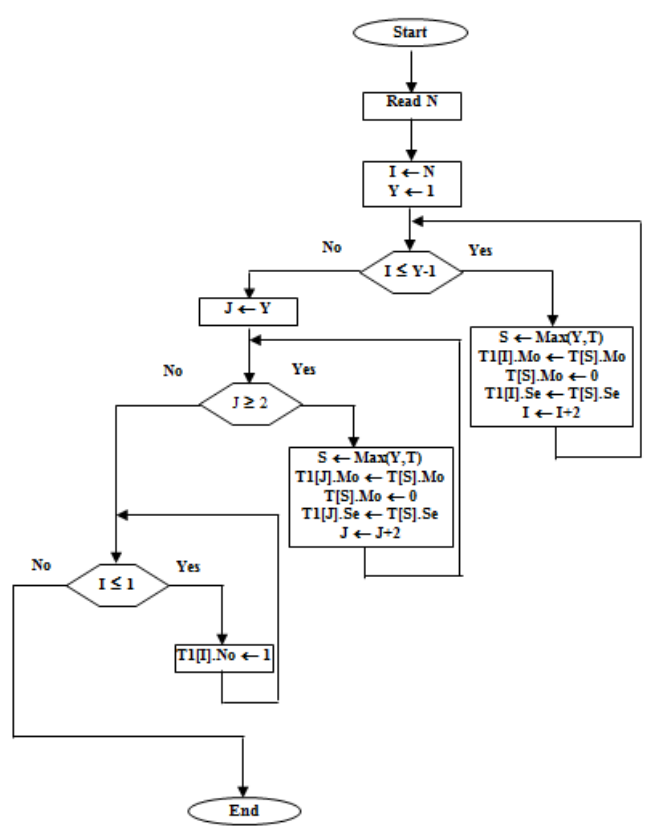

Fig. 5b. Algorithm 2 blades distribution.

The assembly of the blades on the wheel of a rotor of a turbine will be as follows, a decreasing sector alternating heavy blades and light blades (Figure 5b).

On this algorithm (figure 5c) the distribution of the blades will be on two decreasing sectors and alternating heavy blades and light blades.

The algorithm 4 which is represented in Fig. 5d shows that there are 4 decreasing sectors by alternating heavy blades (the maximum value of the static momentum) and light blades (the maximum value of the static momentum). 


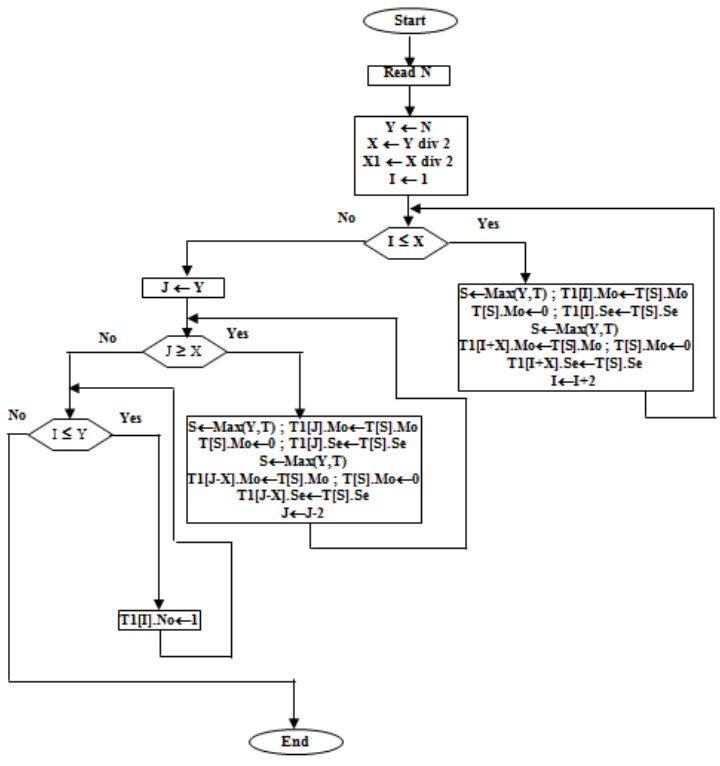

Fig. 5c. Algorithm 3 blades distribution.

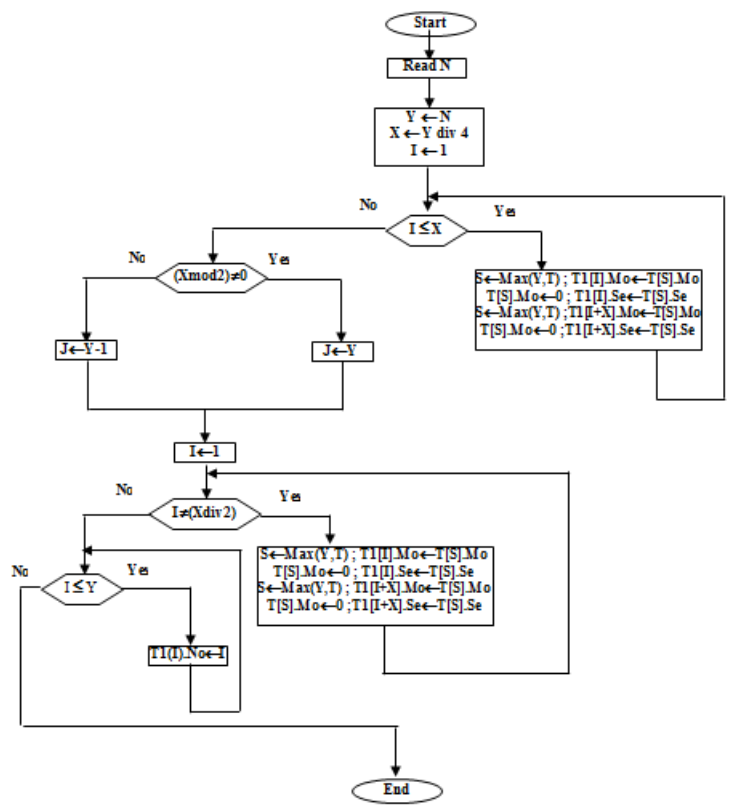

Fig. 5d. Algorithm 4 blades distribution.

Algorithm no. 5 shown in Figure 5e shows that the assembly of the blades follows a distribution that divides the wheel into four decreasing sectors clockwise.

Fig. 5f shows that the assembly of the blades follows a distribution which divides the wheel into three decreasing sectors by alternating heavy blades and light blades.

Table 2 groups the values of the unbalances (correction masses) and the positions of the correction angles obtained from the MATLAB calculation code using the formulas of equations (1) and (2). These values represent the three series of our study (20, 70 and 120 blades). The reading of this table shows that the minimum values of the static moments to correct the unbalance of the rotors which contain 20, 70 and 120 blades are obtained respectively by applying the algorithms 3 , 4 and 6.

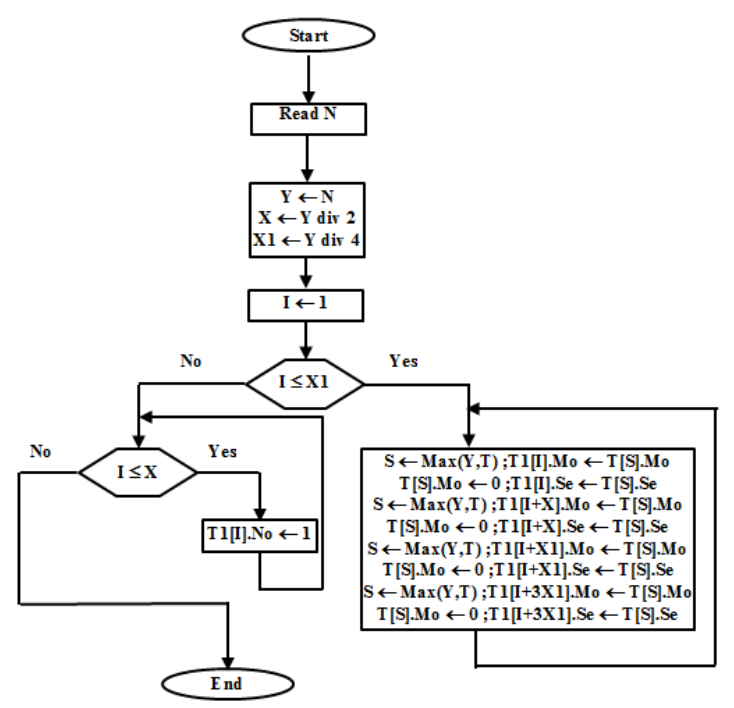

Fig. 5e. Algorithm5blades distribution.

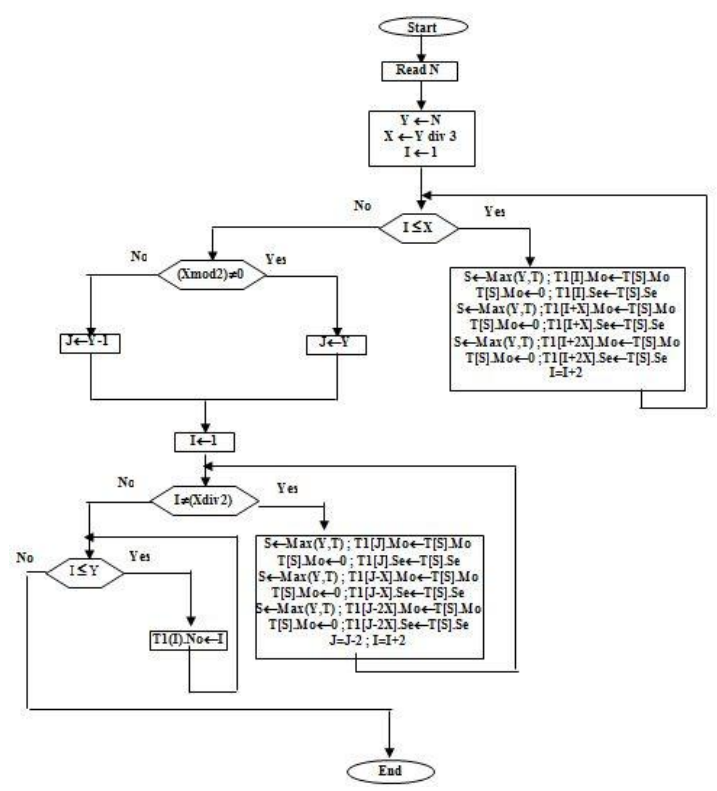

Fig. 5f. Algorithm6 blades distribution.

Table 2. Experimental results

\begin{tabular}{|c|c|c|c|c|c|c|c|}
\hline \multicolumn{2}{|c|}{ Number of blades } & Algo. & Algo. & Algo. & Algo. & Algo. & Algo. \\
\hline \multirow[b]{2}{*}{20} & $U_{c}(\mathrm{~g} \cdot \mathrm{mm})$ & 0.43 & 1.028 & 0.35 & 0.354 & 3.89 & 0.53 \\
\hline & $a_{c}(\operatorname{deg})$ & 52 & 50.6 & 90 & 86 & 26.5 & 70.5 \\
\hline \multirow[b]{2}{*}{70} & $\mathrm{U}_{\mathrm{c}}(\mathrm{g} \cdot \mathrm{mm})$ & 508 & 564 & 53.5 & 19 & 349 & 116 \\
\hline & $\alpha_{c}(\operatorname{deg})$ & 7 & -78 & 82.5 & -14 & 46 & 53 \\
\hline \multirow[b]{2}{*}{120} & $U_{c}(\mathrm{~g} \cdot \mathrm{mm})$ & 69.5 & 178 & 43.6 & 42 & 78.48 & 0.58 \\
\hline & $a_{c}(\operatorname{deg})$ & 42 & 31 & 76.9 & 79 & 67.6 & 63.5 \\
\hline
\end{tabular}



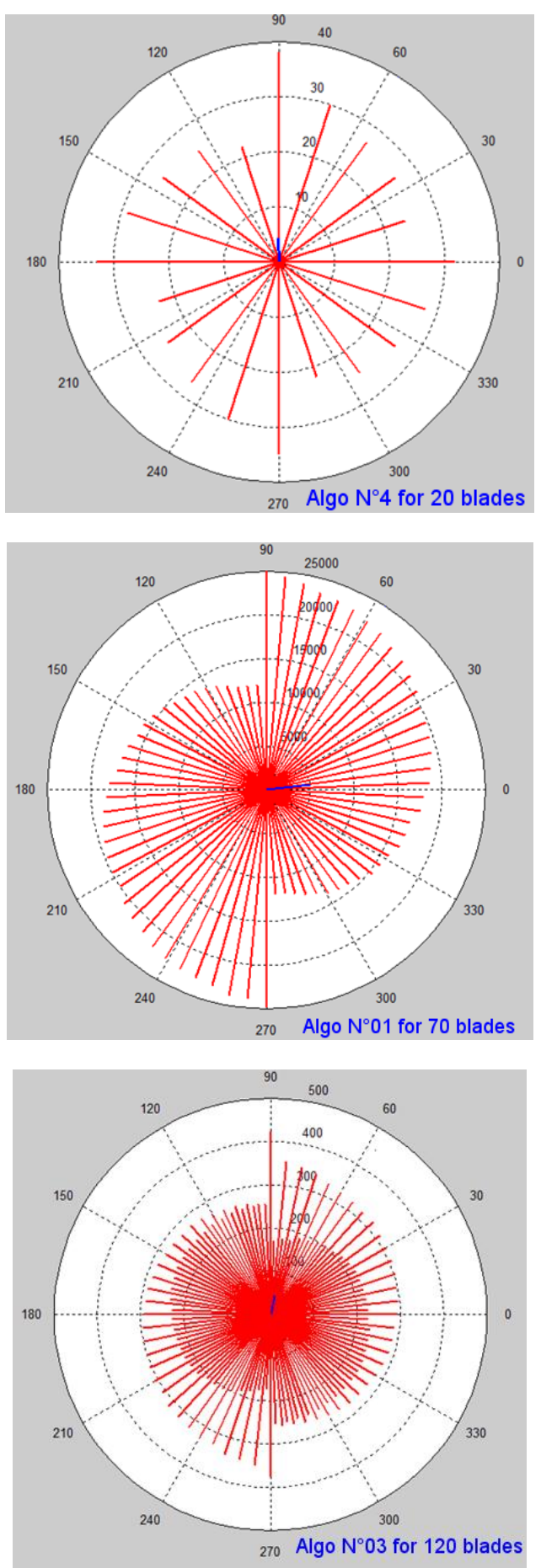

Fig. 6. Graphical simulation results.

Fig. 6 shows each bar which represents the position of a blade in the impeller wheel of the turbine, this representation makes it possible to simulate the mounting of the blades of a rotor wheel of the turbine. Note that each bar has a length that corresponds to the value of the static moment.

From the results given and the figures recorded during the programming, with six algorithms for this study. We draw directly the corrections of the masses and their angles which are translated by the following modules and phases using the formula of the equations 1 and 2 . The values found in Tables 2 are summarized. The reading of this table shows that the masses of the corrections obtained belong to the admissible range.

\section{CONCLUSION}

Through this study which allowed us to make experimental tests which aim at optimizing a distribution of the blades of a stage of the rotors of the turbines in order to reduce the mass of correction (unbalance) and to find the angle of positioning of this mass of correction. We then made the choice of the different predetermined distribution algorithms. Then, we analysed the possibilities of distribution of the vanes with a MATLAB code.

The results obtained with the MATLAB program give an idea of the value of the correction mass that must be added to have a balance of the rotor and the positioning angle of this mass. For the rotors which contain 20,70 and 120 blades the algorithms 3, 4 and 6 respectively give smaller correction masses compared to the other algorithms. Finally, this calculation code can be applied in the industry that uses turbine rotors to produce electricity as well as maintenance workshops for industrial equipment.

\section{Acknowledgements}

The authors would like to thank Pr. Hocine BELHOCHETTE, Physics Department, Faculty of Sciences, University of Mohamed Boudiaf, M'sila (Algeria) for his encouragement and helpful suggestions. The authors would also like to thank the engineers from the MEI SONELAGZ M'sila (Algeria) and Mr. Zohir LAALILI engineers from the CFPA M'sila (Algeria).

\section{REFERENCES}

1. Foiles WC, Allaire PE, Gunter EJ. Rotor balancing. Shock and Vibration, 1998;5(5-6):325-336. http://dx.doi.org/10.1155/1998/648518

2. Zhou S, Shi J. Active balancing and vibration control of rotating machinery: a survey. Shock and Vibration Digest. 2001;33(5):361-371. http://dx.doi.org/10.1177/058310240103300501

3. Amroune S, Mohamad B, Moussaoui M, Saaidi H. Geometric regeneration and mechanical analysis of a gas turbine blade type Frame 9001 GE. Engineering Solid Mechanics. 2018;6(2):105-112. http://dx.doi.org/10.5267/j.esm.2018.3.003

4. Yu X. General influence coefficient algorithm in balancing of rotating machinery. International Journal of Rotating Machinery. 2004; 10(2): 85-90. http://dx.doi.org/10.1155/S1023621X04000090

5. Akimoff NW. Four years of balancing practice. Journal of the American Society for Naval Engineers. 1921; 33(2), 261-267. https://doi.org/10.1111/j.15593584.1921.tb05386.x

6. Gunter EJ. Jackson C. Balancing of rigid and flexible rotors. Fredric F. Ehrich, Krieger Publishing Company, Malabar, Florida 1999. 
7. Zachwieja J. Dynamic balancing of rotors with manual balancers. Diagnostyka. 2014;15(4):59-64.

8. Schneider H. Technique d'équilibrage. Springer Science \& Business Media. 2006.

9. Fleming DP. Balancing of flexible rotors. The Shock and vibration digest. 1991;23(6): 15-23. https://doi.org/ 10.1177/058310249102300604

10. Alauze C. Equilibrageactif des machines tournantes: application aux grandeslignesd'arbres (Doctoral dissertation, Lyon, INSA), 1998.

11. Vande Vegte J. Continuous automatic balancing of rotating systems. Journal of Mechanical Engineering Science. 1964 6(3), 264-269. https://doi.org/10.1243/JMES_JOUR_1964_006_039 02

12. Van de Vegte J, Lake RT. Balancing of rotating systems during operation. Journal of Sound and Vibration. 1978;57(2): 225-235. https://doi.org/10.1016/0022-460X(78)90581-3

13. Van De Vegte J. Balancing of flexible rotors during operation. Journal of Mechanical Engineering Science. 1981;23(5):257-261

14. Bishop RED. On the possibility of balancing rotating flexible shafts. Journal of Mechanical Engineering Science. 1982;24(4):215-220. https://doi.org/10.1243/JMES_JOUR_1982_024_040 02

15. Lee CW, Kim YD. Modal balancing of flexible rotors during operation: design and manual operation of balancing head. Proceedings of the Institution of Mechanical Engineers, Part C: Journal of Mechanical Engineering Science.1987;201(5): 349-355. https://doi.org/10.1243/PIME PROC 1987201134 -02

16. Gosiewski Z. Automatic balancing of flexible rotors, Part I: Theoretical background. Journal of sound and vibration. 1985;100(4):551-567. https://doi.org/10.1016/S0022-460X(85)80006-7

17. Gosiewski Z. Automatic balancing of flexible rotors, Part II: Synthesis of system. Journal of Sound and Vibration. 1987;114(1):103-119. https://doi.org/10.1016/S0022-460X(87)80237-7

18. Lee CW, Joh YD, \& Kim, Y. D. (1990). Automatic modal balancing of flexible rotors during operation: Computer controlled balancing head. Proceedings of the Institution of Mechanical Engineers, Part C: Mechanical Engineering Science, 204(1):19-28. https://doi.org/10.1243/PIME_PROC_1990_204_071 02

19. Sperling L, Ryzhik B, Linz C, Duckstein H. Simulation of two-plane automatic balancing of a rigid rotor. Mathematics and computers in simulation. 2002;58(4-6):351-365. https://doi.org/10.1016/S0378-4754(01)00377-9

20. Sperling L, Ryzhik B, Duckstein H. Single-plain auto-balancing of rigid rotors. Technische Mechanik. 2004;24(1):1-24.

21. Chung J, Ro DS. Dynamic analysis of an automatic dynamic balancer for rotating mechanisms. Journal of Sound and vibration. 1999; 228(5): 1035-1056. https://doi.org/10.1006/jsvi.1999.2456

22. Cade JW. Self-compensating balancing in rotating mechanisms. Design News, 1964;234.

23. Lee J, Van Moorhem WK. Analytical and experimental analysis of a self-compensating dynamic balancer in a rotating mechanism. Journal of dynamic systems, measurement, and control,
1996;118(3):468-475

https://doi.org/10.1115/1.2801169

Received 2019-08-21

Accepted 2019-11-22

Available online 2019-11-25

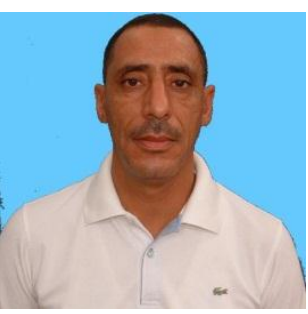

Salah AMROUNE was born in M'sila, Algeria. He received from M'sila University of Algeria his Mechanical state engineer diploma in 1992 and doctorate degree in mechanical engineering from the 08 Mai 1945 Guelma University of Algeria in 2016. His research activities are based on the characterization of natural fibers and bio composites, Plus, modelling and numerical simulation of $\mathrm{CNC}$ machining.

E-mail address: salah.amroune@univ-msila.dz

GoogleScholar:https://scholar.google.com/citations?user= KblTyXwAAAAJ\&hl=fr

ResearchGate:

https://www.researchgate.net/profile/Salah_Amroune ID ORCID: http://orcid.org/0000-0002-9565-1935

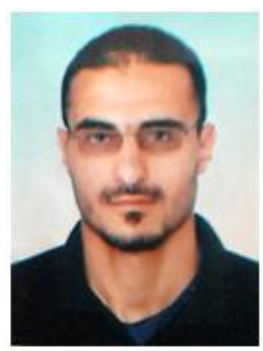

Ahmed BELAADI was born in Guelma, Algeria. He received from University of Guelma Algeria his Mechanical Masterdegree in 2010, and doctorate degree in mechanical engineering from the University of Guelma Algeria in 2015. Currently he works at the University of Skikda Algeria. He is interested in the on the characterization of natural fibers and bio composites.

E-mail address: ahmedbelaadi1@yahoo.fr

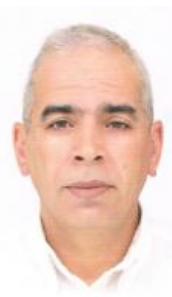

Noureddine MENASRI was born in M'sila, Algeria. He received from University of Boumerdes Algeria his Mechanical engineer diploma in 1988 and doctorate degree in mechanical engineering from the University of Constantine in 2014. He is interested in the field of numerical analysis of mechanical systems.

E-mail address: noureddine.menasri@univ-msila.dz

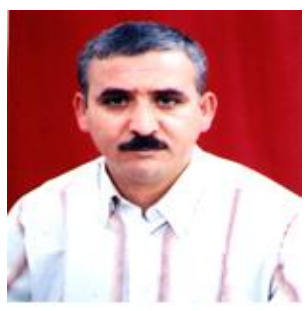

Moussa ZAOUIWAS born in M'sila, Algeria. He received from polytechnicUniversity of Algeria his Mechanical state engineer diploma in 1985 and doctorate degree in mechanical engineering from the Constantine University of Algeria in 2009. His research activities are based on Characterization of the welding joint and welding technique.

E-mail : moussa.zaoui@univ-msila.dz 


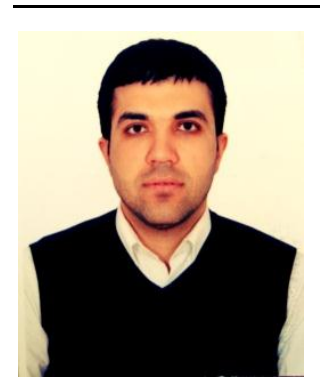

Barhm MOHAMAD received his M.E. degree in Mechanical Engineering in 2012 and start his Ph.D studies in 2016 in Faculty of Mechanical Engineering and Informatics University of Miskolc Hungary, respectively. Since 2018 He has been a technical researcher in the Formula Student-Miskolc at the University of Miskolc, His scientific interests focus on engine powertrain and diagnostics. He has participated in 5 international and 3 national research projects, presenting results of his work at 10 international and 4 national conferences, published more than 11 scientific papers in international and national journals, book chapters, as well as conference proceedings.

E-mail address: pywand@gmail.com

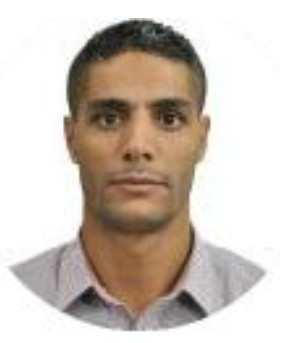

Houari AMIN received his

M.E. degree in Mechanical

Engineering in 2017 at M'sila

University, Algeria and start his Ph.D studies in 2018 in

Faculty of Mechanical

Engineering University of

University of Sidi-Bel-Abbes -

Algeria, His scientific interests

focus on engine powertrain and diagnostics.

E-mail address: amingenie14@gmail.com 